\title{
Acknowledgments
}

As with most academic endeavors this book is a collective effort. First of all, this book would not have been possible without the support of my friends and interlocutors in the field. In Cairo I would especially like to thank Bassam and his family for their hospitality and my former Cairo flat mate, Jeffrey Culang, for his support, advice, and willingness to accompany me to the local café after a long day in the field. I am also grateful to Ben Silsbee, Joel Parker, Yoram Meital, Oren Barak, and Dan Miodownik for their assistance during my fieldwork in Tel Aviv, Beersheba, and Jerusalem. Conducting fieldwork in the Gaza Strip in 2013 was difficult. But it was the friendships I developed in the field that helped me weather through it. I would like to thank Ahmed, Jehad, Bahaa, Hussain, and Sayed for supporting me throughout my stay. I remain humbled by their resilience in the face of adversity, and they will forever be a constant source of inspiration for me. I am also indebted to Omar Shaban and the staff at Pal-Think for Strategic Studies for their support during my stay in Gaza.

I am immensely grateful for the support I received during my studies at the University of Copenhagen from my fellow students Salem Dandan, Lau Øfjord Blaxekjær, Ayca Uygur, Peter Marcus Kristensen, Rune Bennike, Josefine Kühnel Larsen, Kristian Knus Larsen, and Hans Dabelsteen. My supervisor Sune Haugbølle was an invaluable pillar of support. He enthusiastically took on the task of supervising a political science doctoral project that challenged some disciplinary norms and skillfully ferried me through the process of writing and defending the dissertation. Thank you also to Ben Rosamund for helpful feedback on various drafts of the manuscript that became this book. Thanks also to John Collins, Jeroen Gunning, and Noel Parker for their critical reading of earlier drafts that laid the foundations of the book in its current form. I would also like to thank the Danish Institute in Damascus and the Danish Council for Independent Research for funding part of my fieldwork in Palestine.

I thank Lene Hansen, Christian Lund and Mikkel Vedby-Rasmussen at the University of Copenhagen, Cynthia Weber at the University of Sussex, Nicola Pratt and Andre Broome at the University of Warwick as well as Carl Death at the University of Manchester, who read several versions of my book proposal and guided me through the intimidating process of steering this book to publishers. I would also like to thank Jonas, Joe, Magnus, Krista and Johan at Roast Coffee in Copenhagen, who kept me hydrated and caffeinated through long periods of 
intense writing. At Cornell University Press I am grateful to Jim Lance for taking on this book project. His keen interest in this manuscript and his enthusiasm for the final product is the kind of encouragement that fuels young scholars like me.

In the end, an acknowledgement section for this book would be incomplete without a recognition of the contributions of my family. I will remain forever grateful to my in-laws Karen Fog Olwig and Kenneth Robert Olwig for reading and rereading this manuscript. Without their extensive editorial feedback and advice this book would not have been what it is today. My partner Mette Fog Olwig was an invaluable source of support and encouragement as well. A brilliant academic, she read many drafts of this manuscript with a critical eye and her feedback has contributed importantly to the final product, even though I was not always easy to deal with throughout this process. The arrival of our son Shaan Emil and his infectious enthusiasm for life has made me realize that there is more to life than the next book, article, or grant application. Finally, I would like to dedicate this book to my parents Shelley Sen and Pradip Kumar Sen. I am immensely grateful for their enthusiasm for my academic career-this, despite the fact that I reneged on a promise to become an engineer. I see this project as a culmination of their support and the sacrifices they have made for me over the last thirty-five years.

\section{Note on Interviews}

In this book all nonpolitically affiliated interviewees have been assigned pseudonyms in the interest of their security. 


\section{DECOLONIZING \\ PALESTINE}


